\title{
Experimental study on mechanical performance of partially precast steel reinforced concrete beams
}

\author{
Yong Yang ${ }^{\mathrm{a}}$, Yicong Xue $\mathrm{X}^{\mathrm{a} *}$, Yunlong Yu${ }^{\mathrm{a}}$ and Ruyue Liu \\ aSchool of Civil Engineering, Xi' an University of Architecture and Technology, China \\ *corresponding author, e-mail address: xjdxyc@foxmail.com
}

\begin{abstract}
In order to exploit the potentials in mechanical and constructional performance of steel reinforced concrete structures and prefabricated structures, three innovative kinds of partially precast steel reinforced concrete beams, which are abbreviated here as PPSRC, HPSRC and PPCSRC beam, are presented in this paper. The PPSRC beam is composed of two parts, which are the precast outer shell with highperformance concrete and the cast-in-place inner part with common-strength concrete. Meanwhile, on the basis of PPSRC beam, the PPCSRC beam applies castellated steel shape and the HPSRC beam keeps the beam core hollow. With the aim to investigate the mechanical behavior, failure mode and bearing capacity of the PPSRC, PPCSRC and HPSRC beams, a static loading experiment with twenty four specimens was carried out. The effects of aspect ratio, construction method, section shape, concrete flange and strength of concrete were critically examined. Test results indicate that the HPSRC, PPCSRC and PPSRC beams both exhibit similar mechanical performance and bonding performance. The flexural capacity and shear capacity are seldom affected by the construction method and section shape, and increase with the increasing of the cast-in-place concrete strength. The shear strength of the specimens is significantly affected by the concrete flange and aspect ratio.
\end{abstract}

Keywords: Steel reinforced concrete beams; precast concrete; experimental study; flexural performance; shear performance.

\section{Introduction}

Steel reinforced concrete (SRC) structures have been widely applied in large-span or highrise structures due to some favorable characteristics, such as high bearing capacity, great stiffness and outstanding ductility performance [1]. However, because of the complexity of the construction process [2], the use of cast-in-place SRC structure has been limited in conventional residential buildings. Meanwhile, the application of precast concrete structures has increased due to the efficiency and high quality in construction [3].

To solve the problem caused by deficiencies in construction and to promote the application of SRC structures, some researchers have suggested the benefits of combining SRC members and precast concrete members. Hong et al. [4-8] created an innovative partially precast SRC structure system, MHS (modularized hybrid system), and conducted cyclic tests of partially precast steel reinforced concrete (PPSRC) beams. The test results indicated that this PPSRC beam exhibited outstanding mechanical performance, but the structural measures which enhance the bonding performance between the precast concrete, cast-in-place concrete and steel shape should be further optimized. Furthermore, the type and strength of concrete should be altered to match different purposes.

As shown in Fig. 1, three innovative kinds of SRC beams, which are named as partially 
precast steel reinforced concrete (PPSRC) beams, hollow partially precast steel reinforced concrete (HPSRC) beams and partially precast castellated steel reinforced concrete (PPCSRC) beams, are presented in this paper. In PPSRC beams, the outer U-shaped shell, which is composed of steel shape, high-strength concrete, longitudinal and transverse rebar, is prefabricated in work shop, and the inner part could be cast on construction site. In the precast period, modularized foam formwork is attached by special glue on the both flanks of the steel shape with a fixed spacing, and concrete diaphragms would form after the high-strength concrete flowed into the gap between the adjacent formwork, as shown in Fig. 2. The high-strength precast outer part with higher capacity and stiffness could enhance the mechanical performance during the construction period, and the diaphragms could serve as shear connectors to enhance the bonding performance between the precast and cast-in-place concrete. Furthermore, the concrete of the inner part could be cast with the floor slab at the same time with low-strength concrete to enhance the structural integrity and save the consumption of expensive highstrength concrete.

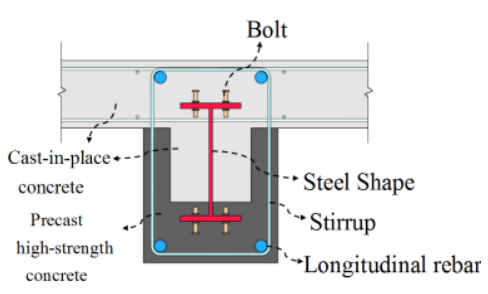

(a) PPSRC beam

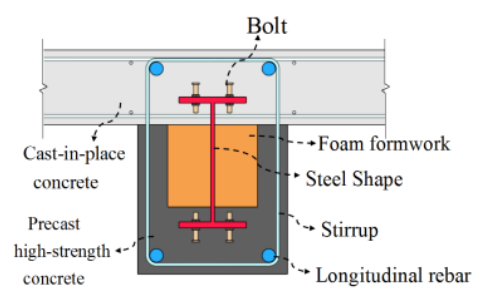

(b) HPSRC beam

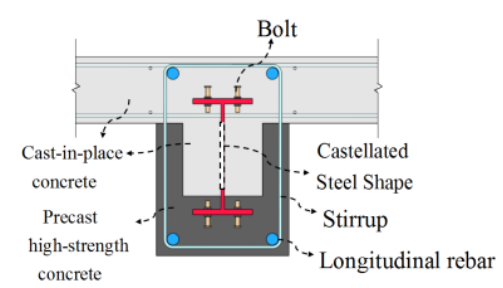

(c) PPCSRC beam

Fig. 1. Diagrams of composite beams.

On the basis of PPSRC beams, HPSRC beams keep the web core hollow to reduce the dead-weight, and the PPCSRC beams apply castellated steel shape to further reduce the dead-weight and enhance the bonding performance between the steel shape and concrete.
To investigate the mechanical behavior of the PPSRC beams, HPSRC beams and PPCSRC beams, a series of static experiments were carried out. In this paper, the effects of the construction method, section shape and compressive strength of concrete are critically examined.

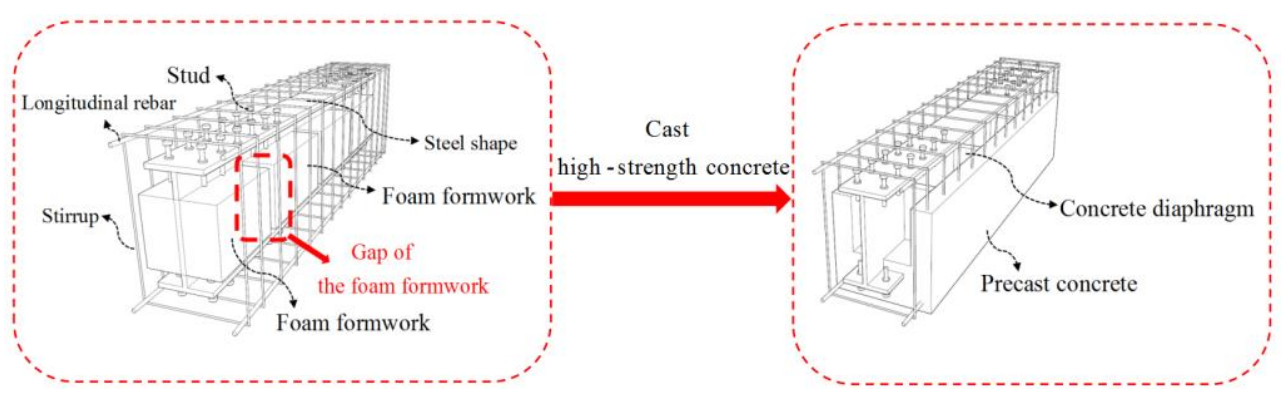

Fig. 2. Diagram of construction process.

\section{Test program}

\subsection{Test specimens}

Twenty four T-beam specimens were designed, including thirteen PPSRC beams, three HPSRC beams, five PPCSRC beams and three cast-in-place RC control specimens. The key parameters are summarized in Table 1.
As illustrated in Fig. 3, the height of the cross section of the PPSRC and HPSRC beams was $300 \mathrm{~mm}$, and that of the PPCSRC beams was $400 \mathrm{~mm}$. The height and the width of the beam web were both $200 \mathrm{~mm}$. The dimensions of the concrete flange of width and thickness were $880 \mathrm{~mm}$ and $100 \mathrm{~mm}$, respectively. The steel shape in PPSRC and HPSRC specimens was HN175 $\times 90 \times 5 \times 8$ of Q235 grade according 
to the Chinese standards. The total height and the width of the steel shape were $175 \mathrm{~mm}$ and $90 \mathrm{~mm}$, respectively, and the thickness of its web and flanges were $5 \mathrm{~mm}$ and $8 \mathrm{~mm}$, respectively. For the PPCSRC specimens, the castellated steel was welded by a malposed steel shape, as shown in Fig. 3(c). The thickness of the concrete diaphragms mentioned above was $150 \mathrm{~mm}$, and the spacing was approximately $500 \mathrm{~mm}$.

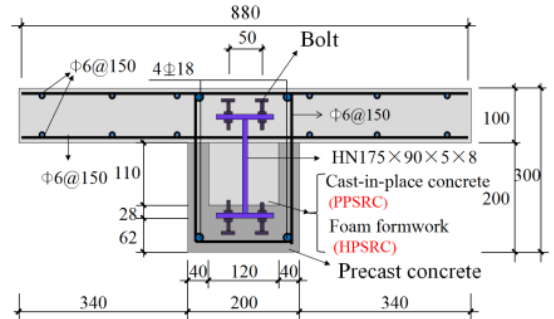

(a) PPSRC and HPSRC beams

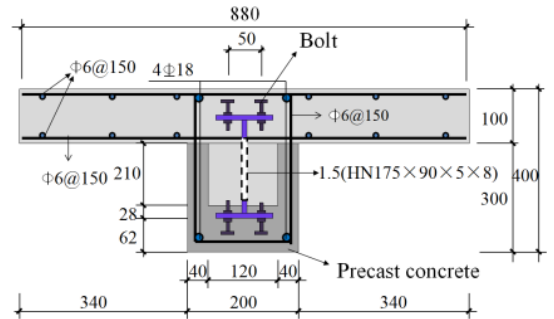

(b) PPCSRC beams

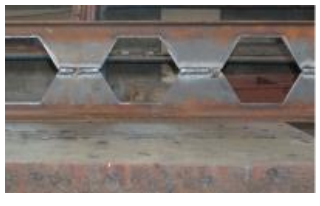

(c) Castellated steel

Fig. 3. Details of the specimens.

Table 1. Matrix of test specimens.

\begin{tabular}{|c|c|c|c|c|c|c|}
\hline Specimen ID & Research & $a(\mathrm{~mm})$ & $\lambda=a / h_{0}$ & $f_{\text {cu,out }}($ MPa) & $f_{\text {cu,in }}(\mathrm{MPa})$ & $P_{\mathrm{u}}(\mathrm{kN})$ \\
\hline PPSRC-1-1 & \multirow{3}{*}{$\begin{array}{c}\text { Flexural } \\
\text { performance }\end{array}$} & 810 & 3.0 & 54.0 & 27.1 & 397 \\
\hline PPSRC-1-2 & & 810 & 3.0 & 54.0 & 38.1 & 416 \\
\hline PPSRC-1-3 & & 810 & 3.0 & 54.0 & 68.0 & 469 \\
\hline PPSRC-2-1 & \multirow{6}{*}{$\begin{array}{c}\text { Shear } \\
\text { performance } \\
\text { (sagging } \\
\text { moment) }\end{array}$} & 270 & 1.0 & 54.0 & 38.1 & 1324 \\
\hline PPSRC-2-2 & & 405 & 1.5 & 54.0 & 38.1 & 919 \\
\hline PPSRC-2-3 & & 486 & 1.8 & 54.0 & 38.1 & 784 \\
\hline PPSRC-2-4 & & 405 & 1.5 & 54.0 & 21.7 & 887 \\
\hline PPSRC-2-5 & & 405 & 1.5 & 54.0 & 68.0 & 988 \\
\hline SRC-2-6 & & 405 & 1.5 & - & 68.0 & 1030 \\
\hline PPSRC-3-1 & \multirow{6}{*}{$\begin{array}{l}\text { Shear } \\
\text { performance } \\
\text { (hogging } \\
\text { moment) }\end{array}$} & 270 & 1.0 & 54.0 & 38.1 & 1024 \\
\hline PPSRC-3-2 & & 405 & 1.5 & 54.0 & 38.1 & 750 \\
\hline PPSRC-3-3 & & 486 & 1.8 & 54.0 & 38.1 & 620 \\
\hline PPSRC-3-4 & & 405 & 1.5 & 54.0 & 21.7 & 632 \\
\hline PPSRC-3-5 & & 405 & 1.5 & 54.0 & 68.0 & 786 \\
\hline SRC-3-6 & & 405 & 1.5 & - & 68.0 & 764 \\
\hline HPSRC-1-1 & \multirow{4}{*}{$\begin{array}{c}\text { Flexural } \\
\text { performance }\end{array}$} & 810 & 3.0 & 54.0 & 27.1 & 365 \\
\hline HPSRC-1-2 & & 810 & 3.0 & 54.0 & 38.1 & 399 \\
\hline HPSRC-1-3 & & 810 & 3.0 & 54.0 & 68.0 & 465 \\
\hline SRC-1-4 & & 810 & 3.0 & - & 68.0 & 487 \\
\hline PPCSRC-1-1 & \multirow{5}{*}{$\begin{array}{c}\text { Shear } \\
\text { performance }\end{array}$} & 365 & 1.0 & 54.0 & 38.1 & 1340 \\
\hline PPCSRC-1-2 & & 550 & 1.5 & 54.0 & 38.1 & 870 \\
\hline PPCSRC-1-3 & & 730 & 2.0 & 54.0 & 38.1 & 664 \\
\hline PPCSRC-1-4 & & 365 & 1.5 & 54.0 & 21.7 & 840 \\
\hline PPCSRC-1-5 & & 550 & 1.5 & 54.0 & 68.0 & 960 \\
\hline
\end{tabular}

Table 2. Material properties of steel.

\begin{tabular}{ccc}
\hline $\begin{array}{c}\text { Type of steel } \\
\text { reinforcement }\end{array}$ & $\begin{array}{c}\text { Yield } \\
\text { strength } \\
\text { (MPa) }\end{array}$ & $\begin{array}{c}\text { Ultimate } \\
\text { strength } \\
\text { (MPa) }\end{array}$ \\
\hline $\begin{array}{c}\text { 8mm-thick steel plate } \\
\text { (flange of steel shape) }\end{array}$ & 273 & 450 \\
5mm-thick steel plate & 262 & 436 \\
(web of steel shape) & 387 & 545 \\
Ø6 rebar & 420 & 578 \\
Ø18 rebar & & \\
\hline
\end{tabular}

\subsection{Material}

The mechanical properties of the reinforcement materials including yield strengths and ultimate strengths are given in Table 2. For all specimens, the strength grades of the concrete in the outer shells were identical, which was C60 graded according to the Chinese code, and the tested compressive strength was 54.0 MPa. The strength grades of 
concrete in the inner-parts were designed at three levels as $\mathrm{C} 20, \mathrm{C} 40$ and $\mathrm{C} 60$, and the tested compressive strengths were $21.7 \mathrm{MPa}$, 38.1 MPa and 68.0 MPa, respectively.

\subsection{Test setup}

A schematic of the test setup is shown in Fig. 4. In the experiments, all the specimens were

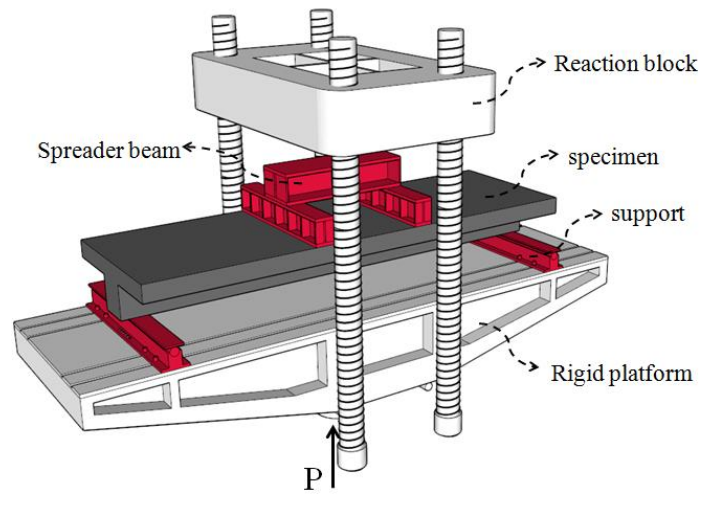

tested on an electro hydraulic servo-testing machine with a maximum capacity of $5000 \mathrm{kN}$, and traditional three-point test and four-point test procedure were applied in specimens according to different aspect ratios.

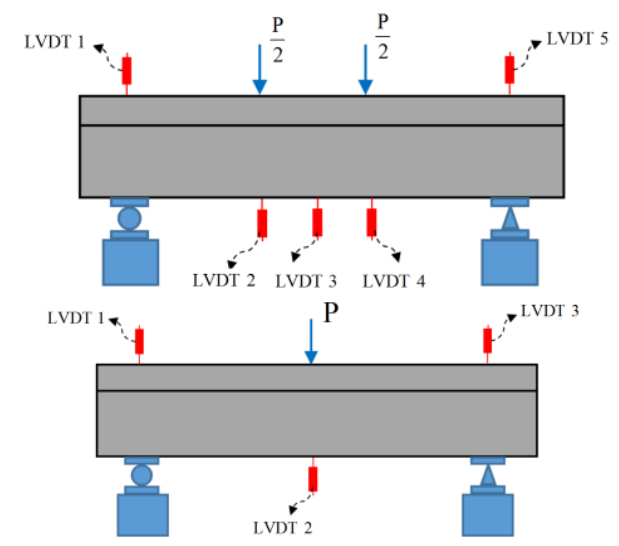

Fig. 4. Diagram of test setup and layout of LVDT.

\section{Discussion of flexural performance of HPSRC and PPSRC beams}

\subsection{Failure modes}

All the specimens of HPSRC and PPSRC series suffered typical flexural failure modes, and the damage patterns of the specimens are shown in Fig. 5. The test results indicated that the PPSRC and HPSRC beams both failed in similar failure modes to the cast-in-place SRC beam. The moment-rotation curves are recorded in Fig. 6, in which the rotation is defined as the deflection at the mid-span dividing the length of the half-span. Fig. 6 indicated that the PPSRC and HPSRC specimens both exhibited outstanding deformability after the peak loads. Some specimens were cut open after the test, and no obvious slippage was observed on the interface between the steel shape and the concrete. It was also hard to distinguish the precast outer-part from the cast-in-place inner-part. This implied that the inner-part and the outer-part were bonded tightly to each other, which attributed to the contribution of the concrete diaphragms.

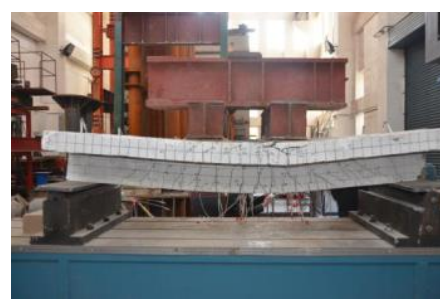

(a) SRC-1-4

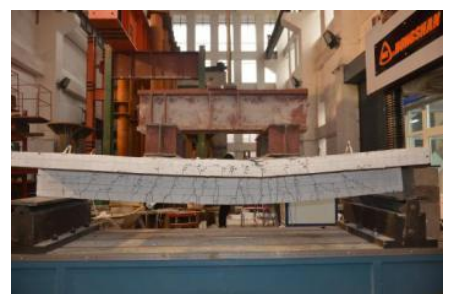

(b) PPSRC-1-3

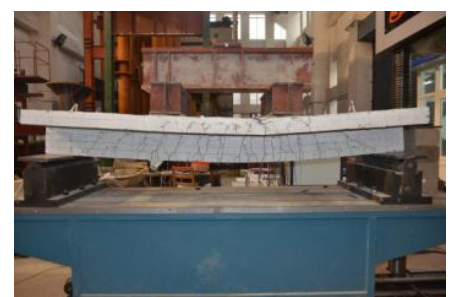

(c) HPSRC-1-1

Fig. 5. Typical failure mode and damage patterns of the PPSRC and HPSRC specimens. 


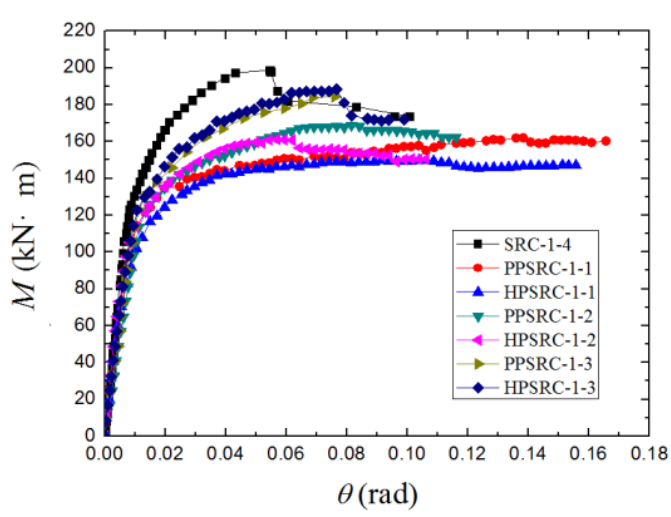

Fig. 6. The moment-rotation curves at the mid-span of the PPSRC and HPSRC specimens.

\subsection{Effect of concrete strength}

Concrete strength directly affects the flexural capacity of PPSRC beams. The strengths of concrete in the outer part of PPSRC and HPSRC specimens are identical, and the strengths of concrete in the inner part of PPSRC and HPSRC specimens are designed as three different grades.

As indicated by the test results of PPSRC1-1, PPSRC-1-2 and PPSRC-1-3, it could be concluded that the flexural capacity increased proportionally to increasing concrete strength but in a mild way with limited room for increase.

\subsection{Effect of hollow core}

As shown in Fig. 7, the flexural capacities of the HPSRC specimens were slightly lower than those of the PPSRC specimens, which indicated that the contribution of the web concrete to the overall flexural capacity is limited. The web concrete of the specimens was in the tension zone during the test due to the existence of the compressive concrete flange.

Therefore, the effect of the hollow core on the flexural performance was relatively small.

\section{Discussion of shear performance of PPSRC and PPCSRC beams}

\subsection{Failure modes}

All the specimens of PPCSRC and PPSRC series suffered typical shear-compression failure modes, and the damage patterns of the

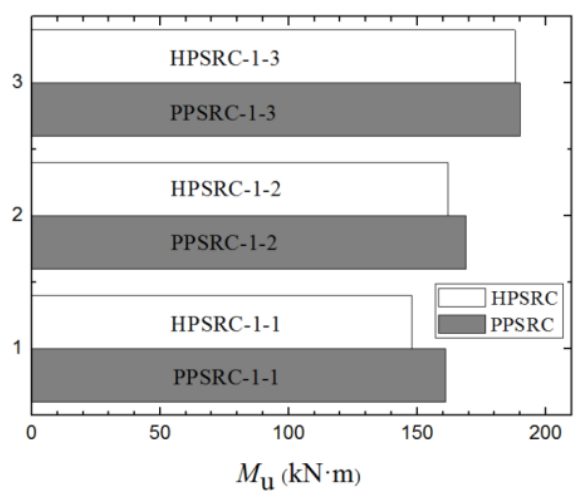

Fig.7. The effect of hollow core.

specimens are shown in Fig. 8. The test results indicated that the PPSRC and PPCSRC beams failed in similar failure modes to the cast-inplace SRC beam. The shear capacity-rotation curves are recorded in Fig. 9. As attributed to the steel shape, all the failure modes were ductile and accompanied with excellent deformation capacity and ductility. The PPSRC specimens under sagging moment exhibited higher shear capacities than those under hogging moment, which indicated that concrete flange directly affected the shear performance. For the PPCSRC specimens, various degree of fracture at the corner of the castellated steel shape was found, as shown in Fig. 8(f).

\subsection{Effect of concrete flange}

For the PPSRC specimens under sagging moment, the concrete flange was in the compression zone, and longitudinal cracks were observed during the test, which indicated that the stress transfer mechanism might be changed due to the concrete flange. For the PPSRC specimens under hogging moment, the concrete flange was in the tension zone, transverse cracks could be observed in the early stage of the test, which meant the concrete flange played a limited role in the shear performance of the specimens under hogging moment. Fig. 10 verified the theory mentioned above, and the contribution by the concrete flange to the shear capacity should be taken into account in PPSRC beams under sagging moment. 


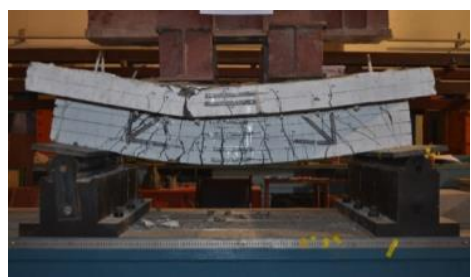

(a) SRC-2-4

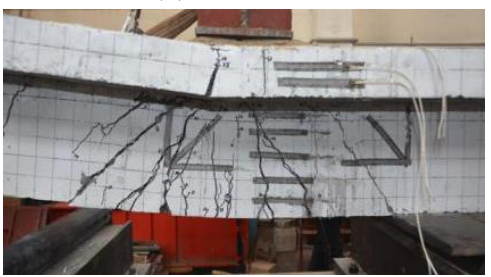

(d) PPCSRC-1-2

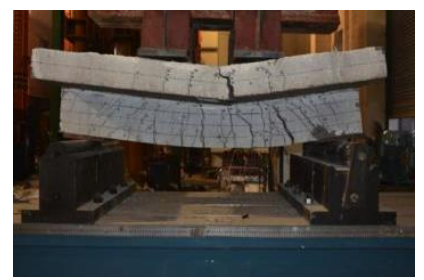

(b) PPSRC-2-5

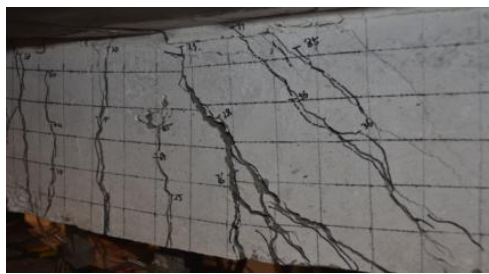

(e) PPCSRC-1-5

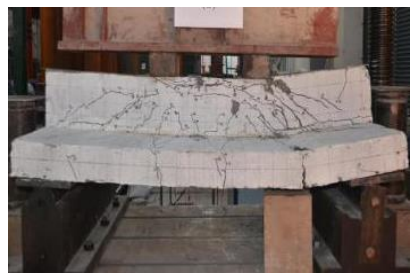

(c) PPSRC-3-5

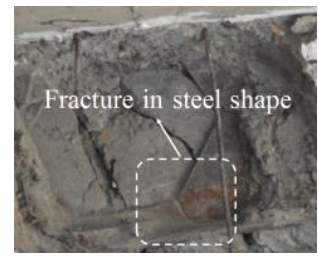

(f) Failure in castellated steel shape

Fig. 8. Typical failure mode and damage patterns of the PPSRC specimens.

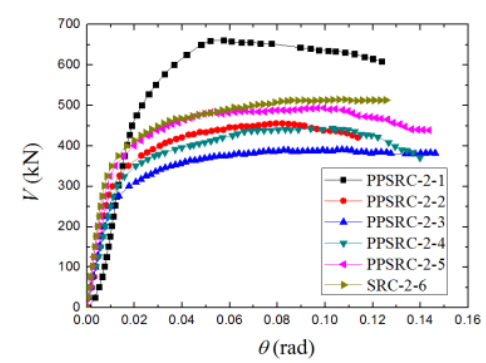

(a) PPSRC beams under sagging moment

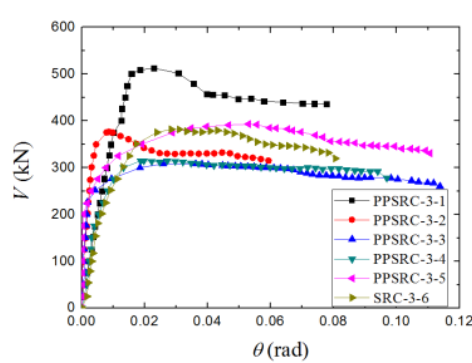

(b) PPSRC beams under hogging moment

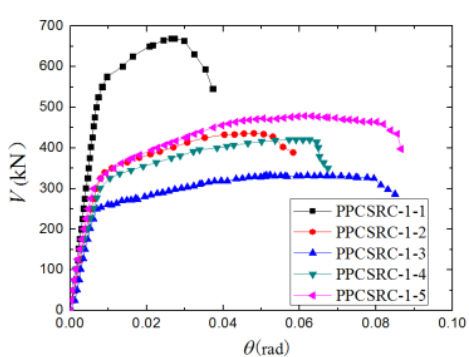

(c) PPCSRC beams under sagging moment

Fig. 9. The shear capacity-rotation curves of the PPSRC and PPCSRC specimens.

\subsection{Effect of concrete strength}

As shown in Fig.11, concrete strength affected the shear capacity of PPSRC and PPCSRC beams in a mild way, because the web of the steel shape could provide sufficient shear resistance and stiffness. Therefore, it could be concluded that the shear capacity increased proportionally to increasing concrete strength but in a mild way with limited room for increase.

\subsection{Effect of steel type}

As mentioned before, the web of the steel shape plays an important role in the shear performance, therefore, the castellated steel shape with hexagonal holes in the web might suffer weaker shear resistance. Nevertheless, the employment of castellated steel shape could enhance the flexural performance of PPCSRC beams because the higher height of the castellated steel shape under the condition of equal steel volume. As indicated in Fig. 12 and Table 1, the shear capacities of the PPCSRC specimens were just slightly lower than those of the PPSRC specimens, which might cause by the extra shear resistance of concrete due to the higher beam web in the PPCSRC beams. Considering that the castellated steel shape could efficiently enhance the flexural capacity, the PPCSRC beam could be regarded as an effective optimization. 


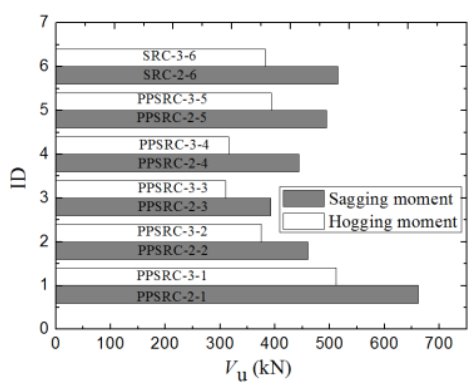

Fig. 10. The effect of the concrete flange.

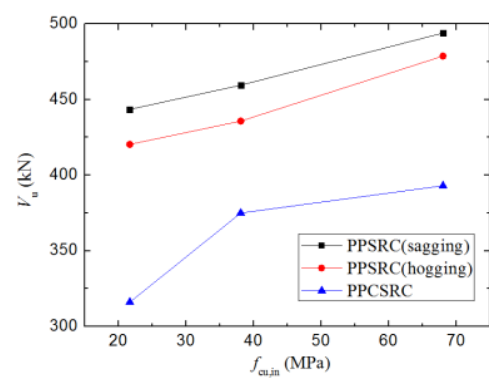

Fig. 11. The effect of the concrete strength.

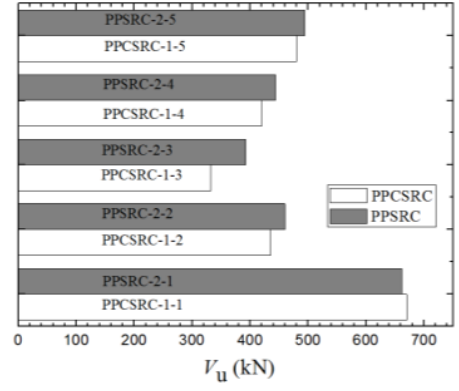

Fig. 12. The effect of steel type.

\section{Conclusions}

A series of experiments thoroughly investigated the flexural and shear performances of both the PPSRC beam, HPSRC beam and PPCSRC beam. The main conclusions drawn from this paper are as follows:

The steel shape, precast concrete and castin-place concrete of both the PPSRC specimens, HPSRC specimens and PPCSRC specimens bonded well during the entire test process, and no obvious slippage was observed. Due to the contribution of the steel shape, all the failure modes were ductile.

The mechanical behaviors of both the PPSRC beam specimens, the HPSRC beam specimens and the PPCSRC beam specimens were similar to those of the cast-in place SRC specimens. The bearing capacities of the PPSRC beam, the HPSRC beam and the SRC beam were similar and seldom affected by construction method.

The flexural capacities of the PPSRC specimens were just slightly higher than those of the HPSRC specimens, and the difference would decrease with an increase in the concrete strength of the inner part. The effect of the hollow core on flexural performance was relatively small.

The concrete strength directly affected the flexural and shear capacity, and the flexural shear capacity of the specimen increased proportionally to increases of the concrete strength but in a mild way with limited room for increase.
The concrete flange directly affected the shear performance of the PPSRC beams. The contribution by concrete flange to the shear capacity should be taken into account in PPSRC beams under sagging moment.

The shear capacities of the PPCSRC specimens were slightly lower than those of the PPSRC specimens under the condition of equal steel volume. Considering that the castellated steel shape could efficiently enhance the flexural capacity, the PPCSRC beam could be regarded as an effective optimization.

\section{References}

[1] Hajjar JF. Composite steel and concrete structural systems for seismic engineering. Journal of Constructional Steel Research 2002; 58(5):703-723.

[2] Xue JY. Design principe of steel and composite structures. Beijing; 2010.

[3] Zhu BF. Introduction of the prefabricated structures. Beijing; 2012.

[4] Hong WK, Park SC, Kim JM, Lee SG, Kim SI, Yoon KJ, Lee HC. Composite beam composed of steel and precast concrete (Modularized Hybrid System, MHS). Part I: experimental investigation. Structural Design of Tall \& Special Buildings 2008; 19(3): 275-289.

[5] Hong WK, Kim JM, Park SC, Kim SI, Lee SG, Lee HC, Yoon KJ. Composite beam composed of steel and precast concrete. (Modularized Hybrid System, MHS) Part II: analytical investigation. Structural Design of Tall \& Special Buildings 2009; 18(8): 891-905.

[6] Hong WK, Park SC, Lee HC, Kim JM, Kim SI, Lee SG, Yoon KJ. Composite beam 
composed of steel and precast concrete (modularized hybrid system). Part III: Application for a 19-storey building. Structural Design of Tall \& Special Buildings 2009; 19(6): 679-706.

[7] Hong WK, Kim SI, Park SC, Kim JM, Lee SG, Yoon KJ, Kim SK. Composite beam composed of steel and precast concrete (modularized hybrid system). Part IV:
Application for multi-residential housing. Structural Design of Tall \& Special Buildings 2010; 19(7): 707-727.

[8] Kim S, Hong WK, Kim JK, Kim JT. The development of modularized construction of enhance precast composite structural systems (Smart Green frame) and its embedded energy efficiency. Energy and Buildings 2013; 66: 16-21. 